\title{
Impact of Maternal Education on the Duration of Breastfeeding and its Association with Various Oral Parameters
}

\author{
Sagar Dahiya ${ }^{1}$, Rajat Mitra ${ }^{2}$, Sanjay M Londhe ${ }^{3}$, Karan Nehra ${ }^{4}$, Tarannum Ghavri ${ }^{5}$, Balakrishna Jayan ${ }^{6}$
}

\begin{abstract}
Aim: Oral diseases have a multifactorial etiology of which environmental factors play a pragmatic role, thereby directly influencing the quality of life. The present study was conducted to find the association between the level of maternal education and the duration of breastfeeding with its effects on the orofacial development of a child.

Materials and methods: This is a cross-sectional retrospective study conducted to find the association between the duration of breastfeeding and various developmental parameters. A total of 650 children were included in this retrospective study conducted at the Army Dental Centre (R\&R). Questionnaires were distributed to the participants (mothers) who were accompanying their child for a routine dental examination. The parameters that were examined are the index of orthodontic treatment need (IOTN), the oral hygiene status, the modified Mallampati index, and posterior crossbites.

Results: Mean duration of breastfeeding in our sample size stood at $44 \%$. The principle mode of oral health awareness is by interactions between family and friends, whereas dental camps at schools or societies influence only $16 \%$ of the respondents. In $41 \%$ of the subjects, there was no need of any treatment according to IOTN, and in $3.1 \%$ of subjects there was great need for treatment. Around $80 \%$ of the subjects maintained reasonably good oral hygiene and $60 \%$ of the subjects were categorized into Mallampati grade I scoring. The level of maternal education follows a reverse trend to the timing of child's first dental visit. About $55 \%$ of the postgraduate mothers got their child for a dental checkup before the age of 5 . About $60 \%$ of the children who were breastfed more than 24 months were having an IOTN of 1 as compared to only $16 \%$ of children who were fed less than 6 months. Posterior crossbites were present in 37\% of children who were fed more than 6 months. About $74 \%$ of the children who were breastfed more than 24 months had Mallampati scoring of 1, whereas only $19 \%$ of the children who were breastfed less than 6 months had the scoring of 1.

Conclusion: A direct association between the level of maternal education and decreased duration of breastfeeding is present, thereby increasing the incidence of moderate-to-severe malocclusion. There is a need to reiterate oral health outreach programs at the community level for basic dental education and healthy practices. The oral hygiene status was directly associated with the higher education group. Formulating and practising a proper breastfeeding schedule can prevent development of various malocclusions especially in lower-income-group countries that still are devoid of specialized care.
\end{abstract}

Keywords: Breastfeeding, Crossbite, Index of treatment need, Mallampati scoring, Maternal education.

Journal of Oral Health and Community Dentistry (2020): 10.5005/jp-journals-10062-0062

\section{INTRODUCTION}

Poor facial esthetics and malocclusion are significant factors engendering a negative impact on self-esteem, self-confidence, and professional competency of an individual. ${ }^{1-4}$ Malocclusion is a condition that has a multifactorial etiology of which breastfeeding has been described in detail under the present literature. Malocclusion has become an ubiquitous condition presently ranked as the third most prevalent oral health problem after dental caries and periodontal disease. ${ }^{5}$ Malocclusion, as defined by the index of orthodontic treatment need (IOTN), occurs in $20-60 \%$ of European adolescents, in $20-50 \%$ of Asians, in $20-40 \%$ of African, and in $20-30 \%$ of South American population. ${ }^{6}$ A pronounced facial muscular activity was determined in infants who were breastfed than the infants who were bottle-fed by analyzing the electrical activity of the masseter muscle using surface electromyography. ${ }^{7}$ Innumerable studies have enthralled the effects of the environmental factors on the incidence of malocclusion. ${ }^{8-10}$ Generally, the onset of malocclusion is during the initial developmental stages and can be summarized as a variation from the normal. Although genetics plays a pivot role, but various epigenetic factors have previously been listed among other etiological factors. ${ }^{11,12}$ The socioeconomic status has a vast
${ }^{1}$ Department of Dentistry Section, Army Dental Corps, Gandhidham, Gujarat, India

${ }^{2}$ Department of Orthodontics, Army Dental Centre, Delhi, India

${ }^{3,6}$ Department of Orthodontics, Army Dental Corps, Delhi, India

${ }^{4}$ Department of Orthodontics and Dentofacial Orthopedics, Armed Forces Medical College, Pune, Maharashtra, India

${ }^{5}$ Department of Pedodontics and Preventive Dentistry, Army Dental Corps, New Delhi, India

Corresponding Author: Sagar Dahiya, Department of Dentistry Section, Army Dental Corps, Gandhidham, Gujarat, India, Phone: +91 9996124443, e-mail: sagardahiya89@gmail.com

How to cite this article: Dahiya S, Mitra R, Londhe SM, et al. Impact of Maternal Education on the Duration of Breastfeeding and its Association with Various Oral Parameters. J Oral Health Comm Dent 2020;14(1):14-21.

Source of support: Nil

Conflict of interest: None

role in modifying the environment of an individual, which can be assessed by the level of maternal education, family income, etc. In developing countries where public healthcare facilities are still at 
the developmental stages, providing treatment to a majority of the patients can be a burden on the economic parameters and as a result in a country like India where 175 million people are living below the poverty line, an orthodontic corrective treatment is only a distant dream. There is still a dearth of literature, which needs to be identified and discovered on the association between maternal education and duration of breastfeeding with its effect on severity of malocclusion and oral hygiene habits.

\section{A Im}

The present study was conducted to find the association between the level of maternal education and the duration of breastfeeding with its effects on the orofacial development of the child.

\section{Objectives}

- To find if any association exists between the level of maternal education and the oral hygiene status.

- Does the severity of malocclusion has any association with the duration of breastfeeding?

- Association between Mallampati scoring and duration of breastfeeding.

- Effect of duration of breastfeeding on development of posterior crossbites.

\section{Materials and Methods}

\section{Study Design}

This is a cross-sectional retrospective study conducted to find the association between the above-mentioned parameters.

\section{Setting}

The study was conducted on a mixed Indian population in a tertiary care military dental establishment. Ethical approval was obtained from the institutional ethical committee. Informed consent forms were distributed to the parents accompanying the children.

\section{Participants}

A total of 650 participants ( 263 with permanent dentition and 387 with mixed or deciduous dentition) from 3 years to 14 years of age who reported at the center for dental checkup were included in the study. The sample size was calculated considering the samples included in the previous studies on maternal education, breastfeeding, and its effect on malocclusion admitting a sample error of $5 \%$, confidence interval of 95 , and design error equal to 2 . In addition, a test power of $80 \%$ with a level of significance of $5 \%$ were considered in the gross and adjusted analyses, thereby obtaining a minimum sample of 620 randomly selected subjects. A bilingual questionnaire was formulated that assessed the socioeconomic status of the child and its effect on the oral health of the individual, which was later validated by four specialists (two orthodontists and two pedodontists). Any recall bias in the age and duration of breastfeeding was cross-checked with the health record cards that are a mandatory requirement in the defense hospitals; moreover, a nari folder is maintained to notify important events in the life of a child and mother providing details of any events that can influence the parameters in the present study. The facility of dental and medical treatment is free of cost; hence, economic bias can be ruled out.

\section{Inclusion Criteria}

- Children between the age group of 3 years and 14 years

- Children accompanied by their mother

- Basic knowledge of Hindi or English

- No previous orthodontic or restorative treatment

- No previous surgical procedure carried out in the head and neck region

- Presence of deciduous or permanent first maxillary and mandibular molars

\section{Exclusion Criteria}

- Children who were not accompanied by their mother

- Children lacking physical or psychological maturity that can restrict the clinical examination or the oral hygiene status

- History of previous orthodontic or rehabilitative treatment

- Absence of first molars

- Individuals on anticholinergic drugs

- Individuals having endocrine abnormalities

- Individuals who were not breastfed due to insufficient maternal milk production

- Unilateral crossbite

\section{Variables}

Clinical examination was carried out by two pedodontists and two orthodontists. The parameters that were examined are IOTN on subjects having permanent dentition, the oral hygiene status, the modified Mallampati index, and posterior crossbites in the first molar region.

\section{EXAMINATION}

The IOTN ratings were calculated on only 263 subjects having permanent dentition and were classified based on the severity from grade I that signifies no treatment required to grade $V$ that denotes very great need of treatment.

Crossbites were measured visually on the patients while they brought their teeth in momentary occlusion at the time of swallowing. Any reduction of buccal overjet less than $0 \mathrm{~mm}$ was marked as posterior crossbite.

The oral hygiene status was measured using oral hygiene index $(\mathrm{OHI})$ for mixed dentition where grade I denotes excellent and grade IV denotes poor condition of oral hygiene.

Mallampati scoring is commonly done by anesthetists to predict the ease of oral intubation. The various etiological factors responsible for higher Mallampati scorings are infections, anatomical, and posture of the tongue. A higher Mallampati scoring can lead to mouth breathing or altered position of the tongue, thereby increasing the chances of malocclusion. An examination was carried out while patients were asked to protrude their tongue and a tongue depressor was used to visualize the posterior oral cavity. In class I soft palate, tonsillar fauces, pillars, and uvula were visible whereas in class II only partial tonsillar fauces were visible. In class III, partial uvula was visible with no visibility of tonsillar fauces and in class IV only hard palate was visible.

\section{Statistics}

Descriptive and analytical statistics were done. The Chi-square test was used to check differences in proportions between groups. 
The level of significant was kept at $p<0.05$. The SPSS (Statistical Package for Social Sciences) Version 22.0 (IBM Corporation, Chicago, USA) software was used for the analysis.

\section{Results}

Tables 1 and 2 and Figures 1 and 2 present the responses of the subjects in which $36 \%$ of the respondent mothers were graduates followed by $27 \%$ of the mothers being postgraduate degree holders. The average duration of breastfeeding in our sample size stood at $44 \%$ for at least $7-24$ months followed by $41 \%$ mothers feeding their child more than 24 months of age. A total of $50 \%$ respondents included in the study were between 6 years and 8 years of age followed by $27 \%$ between 9 years and 11 years of age. The predominant mode of dental awareness is interactions

Table 1: Distribution of the study samples

\begin{tabular}{lcr}
\hline Variables & $n$ & $\%$ \\
\hline Level of education & 73 & \\
Never studied & 170 & 26.2 \\
High school & 234 & 36.0 \\
Graduation & 173 & 26.6 \\
Postgraduation & & \\
Breastfeeding & 0 & 0.0 \\
<1 month & 98 & 15.1 \\
1-6 months & 284 & 43.7 \\
7-24 months & 268 & 41.2 \\
Above 24 months & 116 & \\
Age at which child reported for first specialist opinion & 17.8 \\
3-5 years & 322 & 49.5 \\
6-8 years & 177 & 27.2 \\
9-11 years & 35 & 5.4 \\
12-14 years & & \\
Mode of awareness for availability of orthodontic facilities & \\
Newspapers and TV & 0 & 0.0 \\
Dental camps & 101 & 15.5 \\
Family and friends & 530 & 81.5 \\
Internet & 19 & 2.9 \\
\hline
\end{tabular}

$n$ denotes the number of the subjects

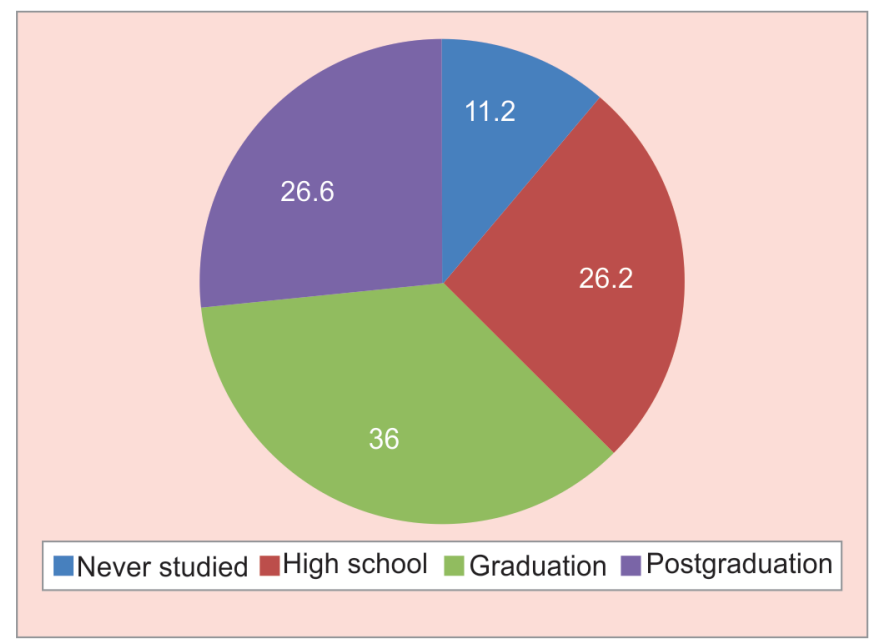

Fig. 1: Distribution of subjects based on the level of education between family and friends; dental camps at schools or societies influence only $16 \%$ of the respondents. In $41 \%$ of the subjects having complete permanent dentition (263), there was no need for treatment according to IOTN and $3.1 \%$ subjects were categorized into great need for treatment. Around $80 \%$ of the total subjects maintained reasonably good oral hygiene and $60 \%$ of the subjects were categorized into Mallampati grade I scoring. Posterior crossbites were present only in $6 \%$ of the population under study.

Table 3 represents the association between the oral hygiene of the child and the maternal education. About $16 \%$ of the subjects belonging to the postgraduate group maintained an excellent oral hygiene as compared to $8 \%$ in the graduation group and none of the subjects maintained an excellent hygiene in the high school or never studied group.

Tables 3 and 4 present the correlation between the level of education and the remaining parameters of the study. According to Figure 3, $100 \%$ of the mothers who never studied, breastfed

Table 2: Distribution of the study samples

\begin{tabular}{lrr}
\hline Severity of malocclusion & $n$ & $\%$ \\
\hline IOTN 1 & 266 & 40.9 \\
IOTN 2 & 153 & 23.5 \\
IOTN 3 & 211 & 32.5 \\
IOTN 4 & 20 & 3.1 \\
IOTN 5 & 0 & 0.0 \\
Oral hygiene status grading & & \\
Excellent & 19 & 2.9 \\
Good & 519 & 79.8 \\
Average & 112 & 17.2 \\
Poor & 0 & 0.0 \\
Mallampati scoring & & \\
Grade I & 389 & 59.8 \\
Grade II & 119 & 18.3 \\
Grade III & 142 & 21.8 \\
Grade IV & 0 & 0.0 \\
Posterior crossbite & & \\
Present & 41 & 93.7 \\
Absent & 609 & \\
\hline
\end{tabular}

$n$ denotes the number of the subjects

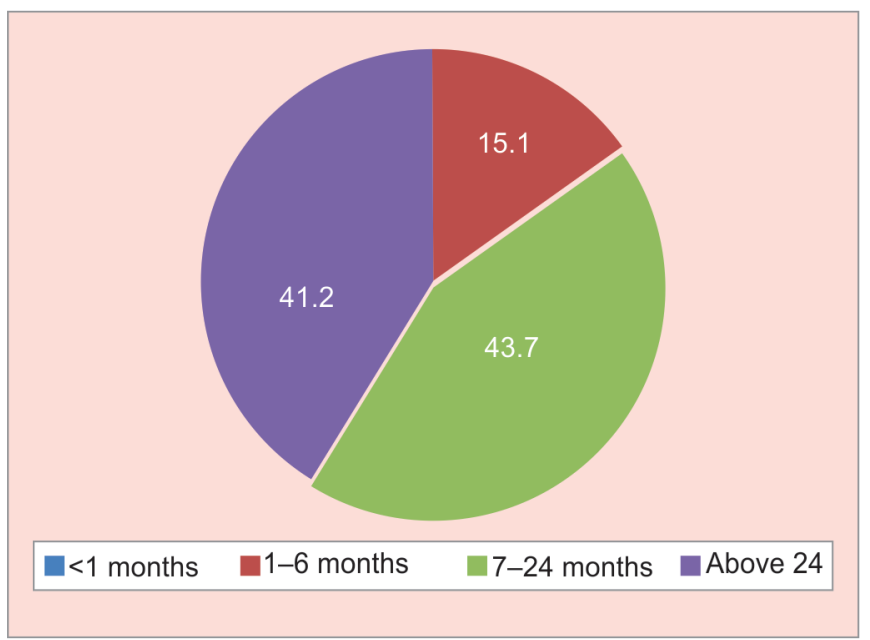

Fig. 2: Distribution of subjects based on the duration of breastfeeding 
Maternal Education and Malocclusion: How are They Linked?

Table 3: Association between the level of education and oral hygiene, Mallampati scoring, and crossbite

\begin{tabular}{|c|c|c|c|c|c|c|}
\hline Oral hygiene status & Never studied & High school & Graduation & Postgraduate & $X^{2}$ value & $p$ value \\
\hline Excellent & $0(0.0)$ & $0(0.0)$ & $19(8.1)$ & $55(16.3)$ & 178.047 & $<0.001^{\dagger}$ \\
\hline Good & 35 (47.9) & $154(90.6)$ & $215(91.9)$ & $115(66.5)$ & & \\
\hline Average & $38(52.1)$ & $16(9.4)$ & $0(0.0)$ & $58(17.2)$ & & \\
\hline Poor & $0(0.0)$ & $0(0.0)$ & $0(0.0)$ & $0(0.0)$ & & \\
\hline Mallampati scoring & & & & & 95.829 & $<0.001^{\dagger}$ \\
\hline Grade I & $73(100.0)$ & $78(45.9)$ & $152(65.0)$ & $86(49.7)$ & & \\
\hline Grade II & $0(0.0)$ & $48(28.2)$ & $48(20.5)$ & $23(13.3)$ & & \\
\hline Grade III & $0(0.0)$ & $44(25.9)$ & $34(14.5)$ & $64(37.0)$ & & \\
\hline Grade IV & $0(0.0)$ & $0(0.0)$ & $0(0.0)$ & $0(0.0)$ & & \\
\hline Crossbites & & & & & 78.659 & $<0.001^{\dagger}$ \\
\hline Present & $0(0.0)$ & $0(0.0)$ & $6(2.6)$ & $35(20.2)$ & & \\
\hline Absent & $73(100.0)$ & $170(100.0)$ & $228(97.4)$ & $138(79.8)$ & & \\
\hline
\end{tabular}

${ }^{*} p$ value derived from the Chi-square test; ${ }^{\dagger}$ significant at $p<0.01$

Table 4: Association between the level of education and breastfeeding, age of reporting, the mode of awareness, and severity of malocclusion

\begin{tabular}{|c|c|c|c|c|c|c|}
\hline \multirow[b]{2}{*}{ Variables } & \multicolumn{4}{|c|}{ Level of education } & \multirow[b]{2}{*}{$X^{2}$ value } & \multirow[b]{2}{*}{$p$ value* } \\
\hline & Never studied & High school & Graduation & Postgraduate & & \\
\hline Breastfeeding & & & & & 351.827 & $<0.001^{\dagger}$ \\
\hline$<1$ month & $0(0.0)$ & $0(0.0)$ & $0(0.0)$ & $0(0.0)$ & & \\
\hline $1-6$ months & $0(0.0)$ & $16(9.4)$ & $2(0.9)$ & $80(46.2)$ & & \\
\hline 7-24 months & $0(0.0)$ & $96(56.5)$ & $95(40.6)$ & $93(53.8)$ & & \\
\hline Above 24 months & $73(100.0)$ & $58(34.1)$ & $137(58.5)$ & $0(0.0)$ & & \\
\hline Age at which child reported for first specialist opinion & & & & & 597.069 & $<0.001^{\dagger}$ \\
\hline $3-5$ years & $0(0.0)$ & $19(11.2)$ & $2(0.9)$ & $95(54.9)$ & & \\
\hline $6-8$ years & $0(0.0)$ & $129(75.9)$ & $137(58.5)$ & $56(32.4)$ & & \\
\hline $9-11$ years & $38(52.1)$ & $22(12.9)$ & $95(40.6)$ & $22(12.7)$ & & \\
\hline $12-14$ years & $35(47.9)$ & $0(0.0)$ & $0(0.0)$ & $0(0.0)$ & & \\
\hline \multicolumn{7}{|l|}{ Mode of awareness for availability of orthodontic facilities } \\
\hline Newspapers and TV & $0(0.0)$ & $0(0.0)$ & $0(0.0)$ & $0(0.0)$ & 128.155 & $<0.001^{\dagger}$ \\
\hline Dental camps & $35(47.9)$ & $31(18.2)$ & $16(6.8)$ & $19(11.0)$ & & \\
\hline Family and friends & $38(52.1)$ & $139(81.8)$ & $218(93.2)$ & $135(78.0)$ & & \\
\hline Internet & $0(0.0)$ & $0(0.0)$ & $0(0.0)$ & $19(11.0)$ & & \\
\hline Severity of malocclusion (on 263 subjects) & & & & & 233.629 & $<0.001^{\dagger}$ \\
\hline IOTN 1 & $73(100.0)$ & $52(30.6)$ & $105(44.9)$ & $36(20.8)$ & & \\
\hline IOTN 2 & $0(0.0)$ & $76(44.7)$ & 42 (17.9) & $35(20.2)$ & & \\
\hline IOTN 3 & $0(0.0)$ & $42(24.7)$ & 87 (37.2) & $82(47.4)$ & & \\
\hline IOTN 4 & $0(0.0)$ & $0(0.0)$ & $0(0.0)$ & 20 (11.6) & & \\
\hline IOTN 5 & $0(0.0)$ & $0(0.0)$ & $0(0.0)$ & $0(0.0)$ & & \\
\hline
\end{tabular}

${ }^{*} p$ value derived from the Chi-square test; ${ }^{\dagger}$ significant at $p<0.01$

their children for more than 2 years followed by $59 \%$ mothers who were graduates. About $41 \%$ of the postgraduate mothers fed their child between 1 months and 6 months and $54 \%$ between 7 months and 24 months. None of the postgraduate mothers fed their child more than 24 months.

Figure 4 represents that the level of education was following an inversely proportional trend in relation to the timing of child's first dental visit with $55 \%$ of the postgraduate mothers getting their children before the age of 5 and notably none of the never studied group got their child for the consultation at this age.

IOTN 5 was not present in any of the respondents according to Figure 5 whereas $11.6 \%$ respondents were categorized into IOTN 4.
Almost $100 \%$ of the subjects of the never studied maternal group were in IOTN 1 whereas only $21 \%$ of the children of postgraduate mothers were categorized into IOTN 1.

Mallampati grade I was present in $100 \%$ of the never studied group and only in 50\% of the postgraduation group. Crossbites were absent in the never studied group whereas they were present in $20 \%$ of the postgraduation group (Fig. 6).

Table 5 presents the association between the duration of breastfeeding and IOTN, Mallampati scoring, oral hygiene, and posterior crossbites. The IOTN was on a higher side with the decrease in duration of breastfeeding. About $60 \%$ of the children who were fed more than 24 months were having IOTN 1 as compared to only 


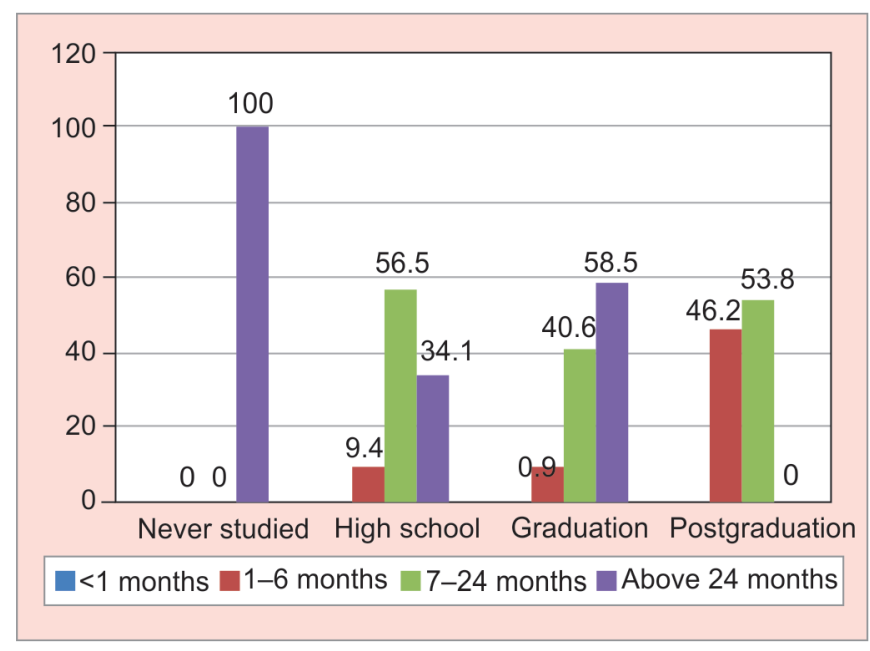

Fig. 3: Association between the level of education and breastfeeding

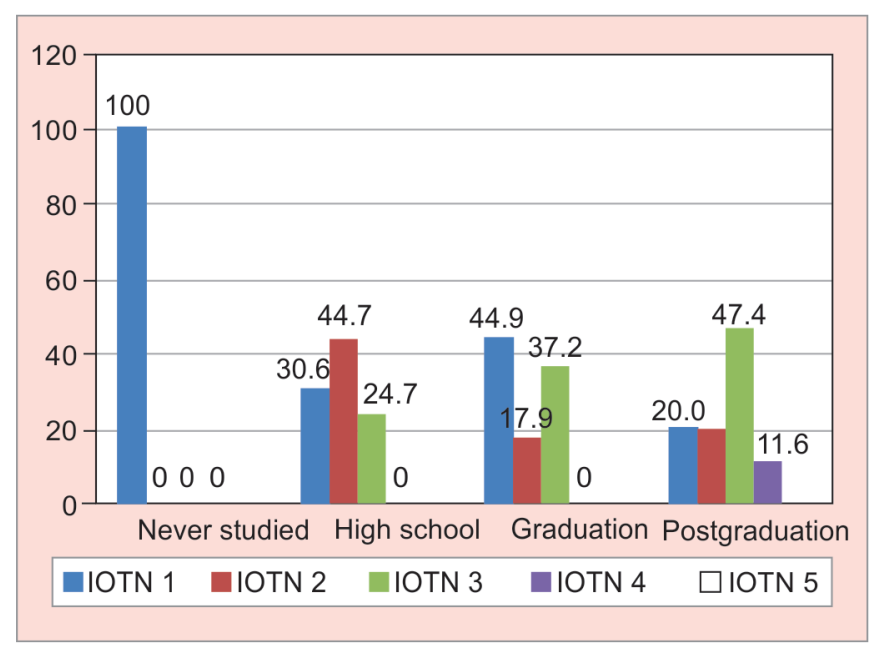

Fig. 5: Association between maternal education and IOTN scoring*, *only conducted on 263 individuals

$16 \%$ of the children who were breastfed less than 6 months. IOTN 4 was prevalent in children who were fed less than 6 months, thereby indicating the role of decreased breastfeeding as an environmental factor in the etiology of malocclusion. Posterior crossbites were present in $37 \%$ of the children who were not breastfed more than 6 months compared to no child having a posterior crossbite who was breastfed more than 24 months. About $74 \%$ of the children who were breastfed more than 24 months had Mallampati scoring of 1 whereas only $19 \%$ of the children who were breastfed less than 6 months had the scoring 1, thereby proving a significant association between higher Mallampati grades and decreased breastfeeding.

\section{Discussion}

This study appraises the effect of breastfeeding on the craniofacial development of a child. Numerous studies have concluded that increased duration of breastfeeding decreases the risk of gastrointestinal tract (GIT) and respiratory system diseases. ${ }^{13,14}$ In addition to protection against infection, it also promotes optimal craniofacial development owing to increased muscular activity. ${ }^{15} \mathrm{~A}$ welldeveloped suckling reflex present in newborns helps the child to stimulate the breast muscles that in turn leads to squirting of milk

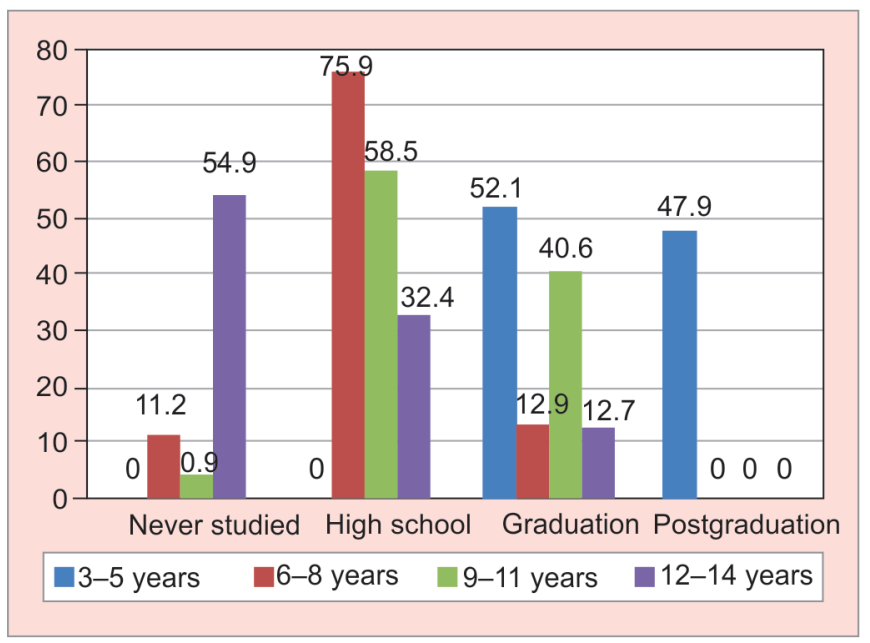

Fig. 4: Association between maternal education and the first dental visit

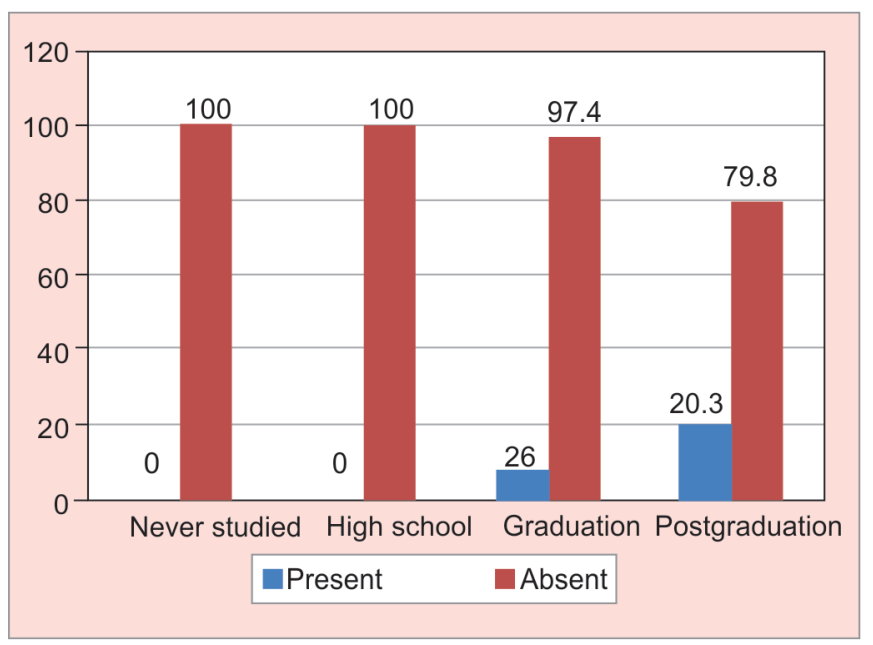

Fig. 6: Association of crossbites with maternal education

and is the only source of nutrition in the early months of life. Various epidemiological studies have highlighted the risk factors associated with the premature cessation of breastfeeding. ${ }^{15}$ The overall development of the orofacial musculature of the child has also been explained by functional matrix hypothesis, which states that form and function are interrelated, i.e., the growth and development of orofacial structures is a result of numerous functions performed by the stomatognathic system during the formative years of life. ${ }^{16}$ Early weaning of a child from breastfeeding leads to more chances of infections and indulgence in various oral habits, thereby disturbing the equilibrium of the orofacial musculature. ${ }^{16}$ Another controversy for the etiological cause of malocclusion is whether genetics is the main decisive factor in the development of malocclusion or the influence of epigenetic stimuli cause these phenotypic alterations in the genetic pattern of growth and development of orofacial structures. ${ }^{17-19}$ About $38 \%$ of 650 children in this study were not fed more than 6 months as compared to only $1.4 \%$ children who were breastfed more than 6 months but less than 24 months. Posterior crossbites were more common in the group of children who were breastfed less as compared to the children who were breastfed for more than 24 months. Similar results were observed in the 
Table 5: Association between the duration of breastfeeding and malocclusion, oral hygiene, Mallampati scoring, and crossbite

\begin{tabular}{|c|c|c|c|c|c|}
\hline \multirow[b]{2}{*}{ Variables } & \multicolumn{3}{|c|}{ Breastfeeding } & \multirow[b]{2}{*}{$X^{2}$ value } & \multirow[b]{2}{*}{$p$ value ${ }^{*}$} \\
\hline & $1-6$ months & 7-24 months & $>24$ months & & \\
\hline Severity of malocclusion & $0(0.0)$ & $0(0.0)$ & $0(0.0)$ & 196.309 & $<0.001^{\dagger}$ \\
\hline IOTN 1 & $16(16.3)$ & $90(31.7)$ & $160(59.7)$ & & \\
\hline IOTN 2 & $16(16.3)$ & $101(35.6)$ & $36(13.4)$ & & \\
\hline IOTN 3 & $46(46.9)$ & $93(32.7)$ & $72(26.9)$ & & \\
\hline IOTN 4 & $20(20.4)$ & $0(0.0)$ & $0(0.0)$ & & \\
\hline IOTN 5 & $0(0.0)$ & $0(0.0)$ & $0(0.0)$ & & \\
\hline Oral hygiene status grading & & & & 57.658 & $<0.001^{\dagger}$ \\
\hline Excellent & $0(0.0)$ & $0(0.0)$ & $19(7.1)$ & & \\
\hline Good & $62(63.3)$ & $246(86.6)$ & $211(78.7)$ & & \\
\hline Average & $36(36.7)$ & $38(13.4)$ & $38(14.2)$ & & \\
\hline Poor & $0(0.0)$ & $0(0.0)$ & $0(0.0)$ & & \\
\hline Mallampati scoring & & & & 109.233 & $<0.001^{\dagger}$ \\
\hline Grade I & 19 (19.4) & $172(60.6)$ & $198(73.9)$ & & \\
\hline Grade II & $23(23.5)$ & $58(20.4)$ & $38(14.2)$ & & \\
\hline Grade III & $56(57.1)$ & $54(19.0)$ & $32(11.9)$ & & \\
\hline Grade IV & $0(0.0)$ & $0(0.0)$ & $0(0.0)$ & & \\
\hline Posterior crossbite & & & & 193.569 & $<0.001^{\dagger}$ \\
\hline Present & $37(37.8)$ & $4(1.4)$ & $0(0.0)$ & & \\
\hline Absent & $61(62.2)$ & $280(98.6)$ & $268(100.0)$ & & \\
\hline
\end{tabular}

${ }^{*} p$ value derived from the Chi-square test; ${ }^{\dagger}$ significant at $p<0.01$

studies conducted by Agrawal et al., ${ }^{20}$ Malandris and Mahoney, ${ }^{21}$ and Larsson. ${ }^{22}$

The consensus on greater prevalence of posterior crossbite in absence of breastfeeding is clear which is rationalized by the movement of the mandible in forward and upward direction along with lowering the tongue, which promotes balanced muscular development. ${ }^{23}$ Another variable, i.e., airway observed in the study, revealed that Mallampati scores of children who were breastfed less were higher than their counterparts. This can be due to lack of development of orofacial musculature and recurrent infections, which can lead to inflammation and enlargement of tonsils. ${ }^{19,20}$ Moreover, decreased Mallampati scoring would lead to better airway and immunity to infection and allergens. ${ }^{24,25}$

In our study, the association between the level of education that was used as a parameter to determine the socioeconomic status of a family and its effects on the orofacial structures was studied and the results were inversely proportional to each other, i.e., more the level of education less is the duration of breastfeeding, thereby leading to altered balance in the orofacial equilibration. This is supported by various epidemiological studies conducted by Bertini et al., ${ }^{15}$ Huang et al., ${ }^{26} \mathrm{Qiu}^{27}{ }^{27}$ Ye et al., ${ }^{28}$ and a metaanalysis conducted by Zhao et al. ${ }^{29}$ However, other studies have also reported that maternal education is positively associated with higher breastfeeding prevalence (Heck et al., ${ }^{30}$ Hornell et al. ${ }^{31}$ )

There is a direct association between the education level of the mother and the oral hygiene of the child (Fig. 7). The brushing and the dietary habits of the mother are directly associated with that of the child. In our study, there was an association between increased maternal education and better oral hygiene of a child and the results were similar to the results of previously conducted studies. ${ }^{32-34}$

Results obtained from this cross-sectional study suggest that breastfeeding reduces the risk of moderate or severe malocclusion on primary, mixed, and permanent dentition on IOTN. The protective effect of exclusive breastfeeding may be explained by

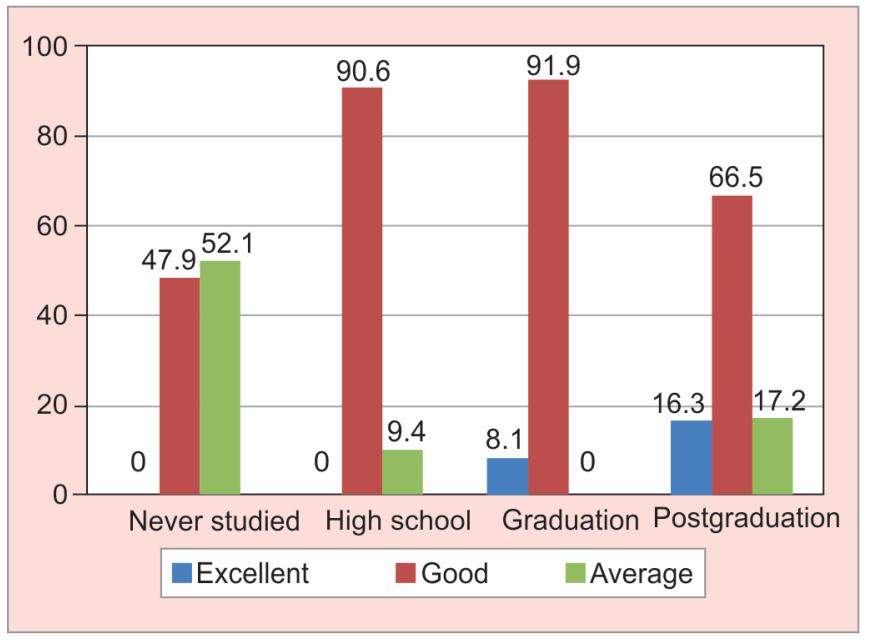

Fig. 7: Association between the level of education and oral hygiene

various mechanisms. First, children who are properly breastfed have more well-developed musculature as compared to children who are not optimally breastfeed. ${ }^{35}$ Second, the brachycephalic mandibular arch format is more common when the child is breastfed, which allows an appropriate tooth eruption position and decreases the chances of malocclusion. ${ }^{36}$ Last, exclusive breastfeeding is strongly and inversely associated with the frequency, intensity, and duration of pacifier use, which in turn may lead to severe malocclusion. ${ }^{20}$

\section{Conclusion}

Maternal education is directly associated with the decreased duration of breastfeeding, which in turn leads to higher chances of malocclusion, Mallampati scoring, and the level of posterior crossbites. 
Still in India we need to improve on the oral health awareness programs and more stress has to be given on the importance of breastfeeding on the overall health of a child by various communitylevel programs targeting lower as well as the higher maternal education groups and more facilities should be provided the public places for breastfeeding of a child.

\section{Limitations OF THE STUDY}

- Socioeconomic status cannot always be related to maternal education as the influence of a father should also be taken into consideration.

- Recall bias for the duration of breastfeeding cannot be excluded from the study.

- Though operator bias has been taken into consideration, multicenter study on a larger population size can provide more accurate results and hence can be generalized on the population.

\section{Declaration of Patient Consent}

The authors certify that appropriate consent has been obtained from the patient/guardian for use of the data obtained from the study wherever necessary and for possible publication.

\section{References}

1. Tatarunaite E, Playle R, Hood K, et al. Facial attractiveness: a longitudinal study. Am J Orthod Dentofacial Orthop 2005;127(6): 676-682. DOI: 10.1016/j.ajodo.2004.01.029.

2. Marques LS, Ramos-Jorge ML, Paiva SM, et al. Malocclusion: esthetic impact and quality of life among Brazilian schoolchildren. Am J Orthod Dentofacial Orthop 2006;129(3):424-427. DOI: 10.1016/ j.ajodo.2005.11.003.

3. Agou S, Locker D, Streiner DL, et al. Impact of self-esteem on the oral-health-related quality of life of children with malocclusion. Am J Orthod Dentofacial Orthop 2008;134(4):484-489. DOI: 10.1016/ j.ajodo.2006.11.021.

4. Pithon MM, Nascimento CC, Barbosa GCG, et al. Do dental esthetics have any influence on finding a job? Am J Orthod Dentofacial Orthop 2014;146(4):423-429. DOI: 10.1016/j.ajodo.2014.07.001.

5. Jordão LM, Vasconcelos DN, Moreira Rda S, et al. Individual and contextual determinants of malocclusion in 12-year-old schoolchildren in a Brazilian city. Braz Oral Res 2015;29(1):3.

6. Tumurkhuu T, Fujiwara T, Komazaki Y, et al. Association between maternal education and malocclusion in Mongolian adolescents: a cross-sectional study. BMJ Open 2016;6(11):e012283. DOI: 10.1136/ bmjopen-2016-012283.

7. França ECL, Sousa CB, Aragão LC, et al. Electromyographic analysis of masseter muscle in newborns during suction in breast, bottle or cup feeding. BMC Pregnancy Childbirth 2014;14(1):154. DOI: 10.1186/14712393-14-154.

8. VonCramon-Taubadel N. Global human mandibular variation reflects differences in agricultural and hunter-gatherer subsistence strategies. Proc Natl Acad Sci U S A 2011;108(49):19546-19551. DOI: 10.1073/ pnas. 1113050108 .

9. Ovsenik M, Farcnik FM, Korpar M, et al. Follow-up study of functional and morphological malocclusion trait changes from 3 to 12 years of age. Eur J Orthod 2007;29(5):523-529. DOI: 10.1093/ejo/cjm065.

10. Proffit WR, Henry W, Fields J, et al. Contemporary orthodontics. 4th ed., Canada, Mosby: Elsevier; 2007. pp. 130-161.

11. Ovsenik M. Incorrect orofacial functions until 5 years of age and their association with posterior crossbite. Am J Orthod Dentofacial Orthop 2009;136(3):375-381. DOI: 10.1016/j.ajodo.2008.03.018.

12. ICOHIRP. Social inequalities in oral health: from evidence to action. Secondary social inequalities in oral health: from evidence to action. 2015. http://www.icohirp.com/monograph.html.
13. Strand TA, Sharma PR, Gjessing HK, et al. Risk factors for extended duration of acute diarrhea in young children. PLoS ONE 2012;7(5):e36436. DOI: 10.1371/journal.pone.0036436.

14. Bachrach VR, Schwarz E, Bachrach LR. Breastfeeding and the risk of hospitalization for respiratory disease in infancy: a meta-analysis. Arch Pediatr Adolesc Med 2003;157(3):237-243. DOI: 10.1001/ archpedi.157.3.237.

15. Bertini G, Perugi S, Dani C, et al. Maternal education and the incidence and duration of breast feeding: a prospective study. J Pediatr Gastroenterol Nutr 2003;37(4):447-452. DOI: 10.1097/00005176200310000-00009.

16. Lydia M, Del Valle L, Singh GD, et al. Associations between a history of breast feeding, malocclusion and parafunctional habits in Puerto Rican children. PRHSJ 2006;1:31-34.

17. Enlow DH, Harvold EP, Latham RA, et al. Research on control of craniofacial morphogenesis: an NIDR state-of-the-art workshop. Am J Orthod 1977;71(5):509-530. DOI: 10.1016/0002-9416(77)90002-1.

18. Graber TM. Thumb and finger sucking. Am J Orthod 1959;45(4): 259-269. DOI: 10.1016/0002-9416(59)90084-3.

19. Karjalainen $\mathrm{S}$, Rönning $\mathrm{O}$, Lapinleimu $\mathrm{H}$, et al. Association between early weaning, non-nutritive sucking habits and occlusal anomalies in 3-YEAR-OLD FinnISH CHILDREN. Int J Ped Dent 1999;9(3):169-173. DOI: 10.1046/j.1365-263x.1999.00133.x.

20. Agarwal SS, Nehra K, Sharma M, et al. Association between breastfeeding duration, non-nutritive sucking habits and dental arch dimensions in deciduous dentition: a cross-sectional study. Prog Orthod 2014;15(1):59. DOI: 10.1186/s40510-014-0059-4.

21. Malandris M, Mahoney EK. Aetiology, diagnosis and treatment of posterior cross-bites in the primary dentition. Int J Paediatr Dent 2004;14(3):155-166. DOI: 10.1111/j.1365-263X.2004.00546.x.

22. Larsson E. Sucking, chewing, and feeding habits and the development of crossbite: a longitudinal study of girls from birth to 3 years of age. Angle Orthod 2001;71(2):116-119. DOI: 10.1043/00033219(2001)0712.0.CO;2.

23. Kobayashi HM, Scavone H,Jr, Ferreira Rl, et al. Relationship between breastfeeding duration and prevalence of posterior crossbite in the deciduous dentition. Am J Orthod Dentofacial Orthop 2010;137(1): 54-58. DOI: 10.1016/j.ajodo.2007.12.033.

24. Gdalevich M, Mimouni D, David M, et al. Breast-feeding and the onset of atopic dermatitis in childhood: a systemic review and meta-analysis of prospective studies. J Am Acad Dermatol 2001;45(4):520-527. DOI: 10.1067/mjd.2001.114741.

25. Gdalevich M, Mimouni D, Mimouni M. Breast-feeding and the risk of bronchial asthma in childhood: a systemic review with meta-analysis of prospective studies. J Pediatr 2001;139(2):261-266. DOI: 10.1067/ mpd.2001.117006.

26. Huang $\mathrm{HT}$, Liang $\mathrm{H}, \mathrm{Hu}$ JW, et al. Breastfeeding and associated factors in five areas of china. J Soochow Uni Med Sci Ed 2012;32(4):454-458. Chinese.

27. Qiu LQ. Factors that influence breastfeeding initiation and duration in urban, suburban and rural areas of Zhejiang Province, Peoples Republic of China. Perth: Curtin University; 2008.

28. Ye JL, Cui Y, Pan XP. Study of the breast feeding and the influence factors in Xinjiang rural areas. Mater Child Health Care China 2007;22(17):2420-2422.

29. Zhao J, Zhao Y, Du M, et al. Maternal education and breastfeeding practices in China: a systematic review and meta-analysis. Midwifery 2017;50:62-71. DOI: 10.1016/j.midw.2017.03.011.

30. Heck KE, Braveman P, Cubbin C, et al. Socioeconomic status and breastfeeding initiation among California mothers. Public Health Rep 2006;121(1):51-59. DOI: 10.1177/003335490612100111.

31. Hornell A, Aarts C, Kylberg E, et al. Breastfeeding patterns in exclusively breastfed infants: a longitudinal prospective study in Uppsala, Sweden. Acta Paediatr 1999;88(2):203-211. DOI: 10.1111/ j.1651-2227.1999.tb01083.x.

32. Bhardwaj SV, Bhardwaj A. Early childhood caries and its correlation with maternal education level and socio-economic status. J Orofac Sci 2014;6(1):53-57. DOI: 10.4103/0975-8844.132582. 
33. Ersin NK, Kocabas EH, Alpoz AR, et al. Transmission of Streptococcus mutans in a group of Turkish families. Oral Microbiol Immunol 2004;19:408-410.

34. Qin M, Li J, Zhang S, et al. Risk factors for severe early childhood caries in children younger than 4 years old in Beijing, china. Pediatr Dent 2008;30(2):122-128.
35. Sánchez-Molins M, GrauCarbó J, LischeidGaig C, et al. Comparative study of the craniofacial growth depending on the type of lactation received. Eur J Paediatr Dent 2010;11(2):87-92.

36. Inoue N, Sakashita R, Kamegai T. Reduction of masseter muscle activity inbottle-fed babies. Early Hum Dev 1995;42(3):185-193. DOI: 10.1016/0378-3782(95)01649-n. 